\title{
PENGARUH TINGKAT KETERGANTUNGAN PASIEN TERHADAP BEBAN KERJA PERAWAT RSPI PROF. Dr. SULIANTI SAROSO
}

\author{
Aditiya Puspanegara \\ Program Studi S1 Ilmu Keperawatan Sekolah Tinggi Ilmu Kesehatan Kuningan Garawangi \\ kuridit@yahoo.com
}

\begin{abstract}
Abstrak
Latar belakang: Fenomena yang terjadi di Indonesia setelah ada kebijakan Jaminan Kesehatan Nasional (JKN). Jumlah kunjungan pasien di rumah sakit melonjak $70 \%$ sehingga dapat mempengaruhi beban kerja perawat dan berakibat langsung terhadap stress perawat. Tujuan: Penelitian ini bertujuan untuk mengabalisis pengaruh tingkat ketergantungan pasien, terhadap beban kerja perawat. Jenis penelitian: Jenis penelitian ini adalah penelitian deskriptif korelatif dengan pendekatan crossectional. Analisis: Sampel penelitian ini adalah perawat yang berdinas di ruang rawat inap dengan jenis ruangan yang berkarakteristik sama jengan jumlah sampel 36 perawat. Analisa data dilakukan dengan menggunakan Chi-Square. Hasil penelitian: Berdasarkan hasil penelitian dapat disimpulkan bahwa ada pengaruh tingkat ketergantungan pasien dengan beban kerja perawat $(P=0,000)$ dan perawat yang mendapatkan pasien yang memiliki ketergantungan parsial 0,3 kali berpeluang membuat beban kerja perawat menjadi produktif $(\mathrm{OR}=0,300)$. Kesimpulan dan saran: Diharapkan pihak rumah sakit membuat supervisi khusus untuk perawat agar dapat lebih meningkatkan produktifitas kerja, dengan supervisi keperawatan dapat meningkatkan pengetahuan dan keterampilan, serta makin terbinanya hubungan antar perawat. Setiap ruang rawat melakukan pengukuran beban kerja perawat secara berkala minimal sekali dalam setahun agar terevaluasinya beban kerja perawat dan tercukupinya jumlah tenaga perawat di ruangan sehingga meminimalisir beban perawat.
\end{abstract}

Kata kunci : Beban Kerja Perawat, Tingkat Ketergantungan Pasien

\section{Pendahuluan}

Perkembangan teknologi pada era globalisasi seperti sekarang ini cukup pesat termasuk teknologi di bidang kesehatan. Penyakit yang masyarakat hadapi menjadi semakin kompleks, dan rumah sakit dituntut memberikan pelayanan dengan baik dan maksimal. Rumah sakit dengan tenaga medis yang ada didalamnya diharapkan mampu melayani masyarakat dengan profesional dan berkualitas. Perawat merupakan salah satu tenaga medis di rumah sakit yang memberikan pelayanan untuk memberikan perawatan kepada pasien dan menunjang kesehatan pasien. Perawat merupakan pekerja yang selalu ada di setiap rumah sakit yang bertanggung jawab atas kesehatan pasien di ruang rawat inap, rawat jalan, atau poliklinik dan pelayanan gawat darurat. Sebagaimana kita ketahui bersama pekerja kesehatan rumah sakit yang terbanyak yang menurut pendapat Hamid (2007) menyatakan bahwa "perawat yang berjumlah sekitar $60 \%$ dari tenaga kesehatan yang ada di rumah sakit". Perawat merupakan sebuah profesi yang jumlahnya selalu mendominasi seluruh rumah sakit dan merupakan ujung tombak pelayanan kesehatan rumah sakit. 
Fenomena yang terjadi di Indonesia setelah ada kebijakan BPJS \& Kebijakan Kartu Jakarta Sehat (KJS) yang diluncurkan Gubernur DKI Jakarta Joko Widodo pada waktu itu membuat sejumlah rumah sakit di Jakarta kekurangan fasilitas dan tenaga medis. Sejak KJS diluncurkan, jumlah pasien melonjak $70 \%$ atau sekitar 500.000 pasien. Akibatnya, antrian pasien panjang bahkan ada yang tidak tertampung (Kusumawati 2015).

Berdasarkan data diatas sudah sangat jelas bahwa jumlah pasien sangat mempengaruhi beban kerja perawat, hal tersebut diungkapkan oleh Gillies (1994) dalam Gian (2012) yang mengatakan bahwa bahwa "faktor- faktor yang mempengaruhi beban kerja adalah jumlah pasien yang dirawat/hari/bulan/tahun dalam suatu unit, kondisi penyakit atau tingkat ketergantungan pasien, rata-rata hari perawatan pasien". Selain mempunyai penyebab, beban kerja perawat juga mempunyai dampak ketika tuntutan melebihi kapasitas dari atasan untuk memenuhi tuntutan tersebut secara memadai. Beban kerja yang terlalu sedikit juga dapat menyebabkan stres kerja. Karena beban kerja yang terlalu sedikit dimana pekerjaan yang terjadi karena pengulangan gerak akan menimbulkan kebosanan, rasa monoton. Kebosanan dalam kerja rutin sehari-hari karena tugas atau pekerjaan yang terlalu sedikit, mengakibatkan kurangnya perhatian dan konsentrasi pada pekerjaan sehingga potensial dapat membahayakan pasien.

\section{Metode Penelitian}

Penelitian ini menggunakan jenis penelitian deskriptif analitik noneksperimental, dengan pendekatan kuantitatif, analisis korelasi dengan pendekatan cross sectional. Penelitian analitik korelasi digunakan karena peneliti ingin mendapatkan gambaran masingmasing variabel penelitian, dan menghubungkan dua variabel dan subvariabel dengan analisis korelasi serta dengan melakukan penelitian sesaat pada waktu tertentu saja (Sastroasmoro \& Ismail, 2008). Variabel bebas adalah tingkat ketergantungan pasien dan variabel terikat adalah beban kerja perawat di ruangan.

Populasi penelitian ini adalah seluruh perawat ruangan yang bekerja di ruangan rawat inap di RSPI Sulianti Sarososebanyak 196 perawat dengan jumlah sampel minimum sebanyak 50 responden.

\section{Hasil Penelitian}

Tabel 1. Distribusi Frekuensi Tingkat Ketergantungan Pasien dan Beban Kerja Perawat di RSPI Prof. Dr. Sulianti Saroso

\begin{tabular}{|c|c|c|}
\hline Variabel & $\begin{array}{l}\text { Frekuensi } \\
\text { (orang) }\end{array}$ & $\begin{array}{c}\text { Persentase } \\
(\%)\end{array}$ \\
\hline \multicolumn{3}{|l|}{ 1. Beban Kerja } \\
\hline Kurang Produktif & 14 & 38,9 \\
\hline Produktif & 22 & 61,1 \\
\hline \multicolumn{3}{|l|}{ 2. Tingkat Ketergantungan Pasien } \\
\hline Minimal & 20 & 55,6 \\
\hline Parsial & 16 & 44,4 \\
\hline
\end{tabular}

Berdasarkan tabel 1. dapat diketahui bahwa untuk variabel tingkat ketergantungan pasien lebih banyak masuk dalam kategori tingkat ketergantungan minimal yaitu sebesar 55,6\%. Begitupula variabel beban kerja lebih banyak masuk dalam kategori beban kerja produktif sebesar $61,1 \%$. 


\section{Tabel 2. Pengaruh Tingkat Ketergantungan Pasien Dengan Beban Kerja Perawat di RSPI Prof. Dr. Sulianti Saroso}

\begin{tabular}{|c|c|c|c|c|c|c|c|c|c|}
\hline \multirow{3}{*}{ Variabel } & & \multicolumn{4}{|c|}{ Beban Kerja Perawat } & & & \multirow{3}{*}{ OR } & \multirow{3}{*}{ Pvalue } \\
\hline & & \multicolumn{2}{|c|}{$\begin{array}{l}\text { Kurang } \\
\text { Produktif }\end{array}$} & \multicolumn{2}{|c|}{ Produktif } & \multicolumn{2}{|c|}{ Total } & & \\
\hline & & $\mathrm{n}$ & $\%$ & $\mathrm{n}$ & $\%$ & $\mathrm{n}$ & $\%$ & & \\
\hline \multicolumn{10}{|c|}{$\begin{array}{l}\text { Tingkat Ketergantungan } \\
\text { Pasien }\end{array}$} \\
\hline & \multirow{2}{*}{$\begin{array}{r}\text { Minimal } \\
\text { Parsial }\end{array}$} & 14 & 70 & 6 & 30 & 20 & 100 & \multirow[t]{2}{*}{0,300} & \multirow[t]{2}{*}{0,000} \\
\hline & & 0 & 0 & 16 & 100 & 16 & 100 & & \\
\hline
\end{tabular}

Berdasarkan tabel 2. dapat diketahui bahwa dari 20 pasien yang memiliki ketergantungan minimal, mengakibatkan beban kerja perawat menjadi kurang produktif sebesar $70 \%$ dan mengakibatkan beban kerja perawat menjadi produktif sebesar $30 \%$. Diketahui pula dari 16 pasien yang memiliki ketergantungan parsial, $100 \%$ membuat beban kerja perawat menjadi produktif.

Berdasarkan hasil analisis chisquare didapatkan data bahwa pvalue 0,000 $<0,05$ yang berarti ada pengaruh tingkat ketergantungan pasien dengan beban kerja perawat, dan perawat yang mendapatkan pasien yang memiliki ketergantungan parsial 0,3 kali berpeluang membuat beban kerja perawat menjadi produktif.

\section{Pembahasan}

Berdasarkan hasil analisis chisquare didapatkan data bahwa pvalue 0,000 $<0,05$ yang berarti ada pengaruh tingkat ketergantungan pasien dengan beban kerja perawat, dan perawat yang mendapatkan pasien yang memiliki ketergantungan parsial 0,3 kali berpeluang membuat beban kerja perawat menjadi produktif.

Berdasarkan analisis menunjukkan bahwa terdapat hubungan antara jumlah pasien dengan beban kerja. Sebagaimana kita ketahui beban kerja perawat adalah seluruh kegiatan atau aktivitas yang dilakukan oleh perawat selama tugas disuatu unit pelayanan keperawatan (Marquis \& Huston, 2000 dalam Sarah 2013). Beban kerja keperawatan pada suatu unit dapat diperkirakan dengan memperhatikan komponen-komponen yaitu jumlah pasien yang dirawat per hari, per bulan dan per tahun, kondisi pasien, ratarata pasien dirawat, tindakan langsung dan tidak langsung yang dibutuhkan pasien, frekwensi masing-masing tindakan yang diperlukan dan rata-rata waktu yang dibutuhkan dalam melaksanakan tindakan (Gillies, 1994 dalam Sutarni 2008).

Beberapa hasil penelitian yang berkaitan dengan beban kerja yaitu hasil penelitian yang dilakukan oleh Trisna (2007) di rumah sakit Haji Jakarta. Didapatkan bahwa kegiatan perawatan tidak langsung merupakan kegiatan yang banyak dilakukan di ruang rawat inap dan faktorfaktor yang mempengaruhi beban kerja adalah jumlah pasien yang dirawat, jumlah perawat yang bertugas, dan banyaknya aktivitas keperawatan langsung dan tidak langsung.

Hal ini juga terjadi pada hasil penelitian (Sudirman, 2013) di rumah sakit DR. Muhammad Hoesin Palembang bahwa variabel yang mempunyai hubungan bermakna dengan beban kerja adalah jumlah kegiatan, rata-rata waktu perawatan tidak langsung serta sistem penugasan dan fasilitas. Dari hasil penelitian diatas dapat disimpulkan bahwa beban kerja disuatu rumah sakit tidak bisa disamaratakan karena setiap rumah sakit mempunyai karakteristik yang berbeda sehingga setiap rumah sakit sebaiknya menghitung beban kerja untuk memperbaiki atau meningkatkan kualitas. Hal ini seperti pendapat Gillies (1994) bahwa para ahli setuju bahwa untuk memperbaiki kualitas 
dan mengurangi biaya perawatan, manajer keperawatan harus mendefinisikan beban kerja dengan lebih akurat serta menugaskan perawat dengan jumlah dan katagori yang tepat, dan harus menimbang beberapa variabel penting yaitu populasi pasien, tindakan perawatan yang dilakukan masingmasing pasien, metode pemberian asuhan keperawatan, kemajuan keperawatan yang mendukung, fasilitas dan iklim sosial tempat perawatan diberikan (Trisna 2007)

\section{Saran}

Beban kerja di ruangan perlu dikelola dengan tepat dengan memperhatikan kondisi pasien yang dirawat, jenis dan lama tindakan yang dibutuhkan pasien, metode asuhan keperawatan yang digunakan, alat/fasilitas yang tersedia, kebutuhan tenaga baik jumlah dan kemampuannya. Sehingga diharapkan perawat pelaksana yang berdinas mendapat keseimbangan antara kemampuan dan pekerjaan yang diterima menjadi tanggung jawabnya serta jumlah perawat yang dibutuhkan dalam menjalankan asuhan keperawatan. Untuk memperbaiki kualitas dan mengurangi biaya perawatan, manajer keperawatan harus mendefinisikan beban kerja dengan lebih akurat serta menugaskan perawat dengan jumlah dan katagori yang tepat, dan harus menimbang beberapa variabel penting yaitu populasi pasien, tindakan perawatan yang dilakukan masing-masing pasien, metode pemberian asuhan keperawatan, kemajuan keperawatan yang mendukung, fasilitas dan iklim sosial tempat perawatan diberikan.

Berdasarkan uraian diatas maka diperlukan pengelola perawat mulai dari kepala ruang sampai kepala bidang keperawatan yang memperhatikan, menganalisa, mengevaluasi dan melakukan perbaikan beban kerja perawat pelaksana di setiap jenis pelayanan keperawatan. Selain itu kepuasan kerja perawat pelaksana juga harus diperhatikan dan difasilitasi dalam memberikan asuhan keperawatan yaitu kepuasan kerja pada aspek prestasi, penghargaan, tanggung jawab, pekerjaan dan kemampuan berkembang sehingga perawat bekerja dengan perasaan senang yang tercermin pada sikap dalam memberikan asuhan keperawatan kepada pasien.

\section{Referensi}

Abdillah, Willy dan Jogiyanto Hartono. (2014). Partial Least Square (PLS). Yogyakarta: Andi.

Aditama, T. Y. (2000). Manajemen Administrasi Rumah Sakit. Penerbit UI Press. Jakarta.

Adji, Irwan. (2012). Faktor-faktor Yang Berhubungan Dengan Kinerja Perawat di Ruang Rawat Inap RSU Raden Mattaher Jambi. Tesis Program Studi Ilmu Kesehatan Masyarakat Program Pasca Sarjana UI. Depok

Ambarwati, Diah. (2014). Pengaruh Beban Kerja terhadap Stres Perawat IGD dengan Dukungan Sosial sebagai Variabel Moderating (Studi pada RSUP dr. Kariadi Semarang). Semarang: Universitas Diponegoro.

Arnold, John et al. (1995). Work Psychology Understanding Human Behavior In The Work Place. Second Edition. London: Pitman Publishing.

Asad, Nargis \& Khan, Saiqa. (2003). Relationship Between Job-Stress and Burnout: Organizational Support and Creativity As Predictor Variables. Pakistan Journal of Psychological Research. ProQuest Psychology Journals.

Asmadi. (2005). Konsep Dasar Keperawatan. Jakarta: Penerbit Buku Kedokteran EGC.

Aviantono, (2009). Pengembangan Sistem Informasi Perencanaan Kebutuhan Tenaga Kesehatan Puskesmas Berdasarkan Beban Kerja di Dinas Kesehatan Kota Bandar Lampung, 
Jurnal Keperawatan, Volume I Nomor 2 tahun 2009.

Balfour, Danny L \& Wechsler, Barton. (1996). Organizational Commitment: Antecedents and Outcomes in Public Organizations. Public Productivity \& Management Review. Vol.19

Carayon, P. \& Alvarado, C. (2007). Workload and Patient Safety Among Critical Care Nurse: Systems Engineering Initiative for Patient Safety. Crit Care Nurs Clin North Am. http://d.scribd.com/docs/ 218ia37tlzcf0u7vve.pdf, tanggal 9 Feb 2017

Coverman, Shelley. (1989). Role overload, Role Conflict, and Stress: Addressing Consequences of Multiple Role Demands. Social Forces. Academic Research Library.

Dahlan, S. (2008). Langkah-langkah Membuat Proposal Penelitian Bidang Kedokteran dan Kesehatan: Seri Evidence Based Medicine. Seri 3. Jakarta: Sagung Seto.

Debora, Andhika. \& M Sitorus. (2012). Gambaran Faktor-Faktor Yang Berhubungan Dengan Kinerja Pegawai Instalasi Laboratorium Klinik RSUP Fatmawati. Depok: FIKM UI

DepkesRI. (2009). Sistem Kesehatan Nasional. Jakarta

Desiana, Putri Mega. (2006). Pengaruh Role Stressor dan Persepsi Mengenai Dukungan Organisasi Terhadap Kepuasan Kerja dan Komitmen Asisten Dosen di FEUI. Jakarta: Magister Manajemen Fakultas Ekonomi Universitas Indonesia.

Deviana, Gian Tareluan. (2016). Hubungan Antara Beban Kerja Dengan Gangguan Pola Tidur Pada Perawat di Instalasi Gawat Darurat Non Trauma RSUP Prof dr. R. D. Kandou Manado.

Dyah Ratih Kanestren. (2009). Analisis Hubungan Karakteristik Individu Dan Lingkungan Kerja Dengan Kinerja
Perawat di Unit Rawat Inap RS Pertamina Jaya.

Gian, Nurmaindah Hendianti. (2012). Gambaran Beban Kerja Perawat Pelaksana Unit Instalasi Gawat Darurat Rumah Sakit Muhammadiyah Bandung. Bandung: Unpad

Gibson, James. (1996). Perilaku, Struktur, Proses Organisasi. Erlangga. Jakarta

Gillies, D.A. (1994). Nursing Management A System Approach. 3rd ed. Philadelphia: W.B. Saunders Company

Gitosudarmo, I \& Sudita, I.N. (2008). Perilaku keorganisasian (Edisi pertama).

Yogyakarta. BPFE-Yogyakarta

Hamid, A.Y. (2007). Rencana Strategik Keperawatan. PPNI

Handoko, Hani. (2010). Manajemen Personalia \& Sumberdaya Manusia, Edisi kedua. Yogyakarta: BPFE UGM.

Hasibuan, Malayu. (2008). Manajemen Sumber Daya Manusia. Jakarta: PT Bumi Aksara.

Hastono, S.P. (2007). Analisis Data Kesehatan: Modul Analisis Data. Jakarta: FKM UI.

Hidayat, Aziz Alimul. (2008). Pengantar Konsep Dasar Keperawatan. Jakarta: Salemba Medika

Huber D.L., (2006). Leadership And Care Management (3nd ed.). Philadelpia Elsevier (USA)

Ilyas, Y. (2006). Perencanaan SDM Rumah Sakit Teori, Metoda dan Formula. Depok : FKM Universitas Indonesia

Irwady. (2007). Penilaian Beban Kerja Perawat. //http://www.scribd.com/ doc/36043707/Penilaian-Beban-Kerja diakses tanggal 14 Januari 2017

Jauharia atika. (2015). Dampak Role Conflict, Role Ambiguity, dan Role Overload Terhadap Judgment Auditor.

Jonni Syah R. (2011). Faktor-faktor Yang Berhubungan Dengan Kinerja 
Petugas Gizi Puskesmas di Kota Pontianak dan Kabupaten Pontianak Tahun. Tesis Program Pasca Sarjana UI. Depok

Komite Etik Nasional Penelitian Kesehatan. (2007). Etika Penelitian Kesehatan. 20 Maret 2017. http//:www.litbang.depkes.co.id.

Kopelman, R. (1986). Managing Productivity in Organizations: a Practical, Peopleoriented Perspective. McGraw-Hill. New York Kusumawati Diana. (2015). Hubungan Beban Kerja Dengan Kinerja Perawat di Ruang IGD RSUD Blambangan Banyuwangi.

Margiati, Lulus. (1999). Stres Kerja: Latar Belakang Penyebab Dan Alternatif. Pemecahannya. Jurnal Masyarakat, Kebudayaan dan Politik. Surabaya: PT. Citra Media

Marquis. (2010). Kepemimpinan dan Manajemen Keperawatan Teori Dan Aplikasi. Jakarta: Salemba Medika
Mitchell, R. Terence. (1978). People in Organization: Understanding Their Behavior. McGraw-Hill Inc

Mohammed G. Alghamdi.(2016). Nursing Workload: a Concept Analysis. Community Practitioner.

Munandar, M. (2011). Budgeting, Perencanaan Kerja Pengkoodinasian Kerja. Pengawasan Kerja. Edisi Pertama. BPFE Universitas Gajah Mada. Yogyakarta

Narbuko, C.\& Achmad, A. (2005). Metodologi penelitian. Jakarta: Bumi Aksara

Newstorm Davis, Keith, \& John W. (1996). Perilaku Dalam Organisasi. Jakarta: Erlangga.

Notoatmodjo, Soekidjo. (2010). Metodologi Penelitian Kesehatan Edisi Revisi. Jakarta: Rineka Cipta

Notoatmodjo, $\quad$ Soekidjo. (2009). Pengembangan Sumber Daya Manusia. Jakarta : PT. Rineka Cipta

Nugraeni R. (2014). Hubungan Antara Role Overload Dengan Stres Kerja Pada Perawat 